\title{
Re-Assessing Tuberculin Skin Test (TST) for the Diagnosis of Tuberculosis (TB) among African Migrants in Western Europe and USA
}

\author{
Kebede C. Shero', Mengistu Legesse², Girmay Medhin², Mulugeta Belay ${ }^{1,2}$, Gunnar Bjune, \\ Fekadu Abebe ${ }^{*}$ \\ ${ }^{1}$ University of Oslo, Faculty of Medicine, Institute of Health and Society, Department of Community Medicine, \\ Oslo, Norway \\ ${ }^{2}$ Addis Ababa University (AAU), Aklilu Lemma Institute of Pathobiology (ALIPB), Addis Ababa, Ethiopia \\ Email: fekadu.abebe@medisin.uio.no
}

Received 9 December 2013; revised 10 January 2014; accepted 21 January 2014

Copyright (C) 2014 by authors and Scientific Research Publishing Inc.

This work is licensed under the Creative Commons Attribution International License (CC BY). http://creativecommons.org/licenses/by/4.0/

(c) (i) Open Access

\section{Abstract}

Background: Tuberculin skin test (TST)-is widely used for screening tuberculosis TB in migrants from high endemic countries of Africa and Asia. However, the cut-off point for clinical TB and Mtb infection is not well established in TB endemic countries of sub-Saharan Africa. In this study we compared the size of TST induration in smear positive pulmonary TB (PTB) patients, their household contacts and community controls in high endemic setting in Ethiopia. Methods: In a health facility-based cross-sectional study, smear positive PTB patients were recruited. Their household contacts traced, and community controls were recruited from neighbourhoods. Sputum sample collected from patients were examined using smear microscopy. Participants were also tested by TST and QuantiFERON ${ }^{\circledR}$-TB Gold In-Tube test (QFTGIT). Results: From a total of 224 study participants, skin test induration data were available for 48 PTB patients, 88 household contacts and 75 community controls. All 48 patients, $64(72.2 \%)$ of the household contacts and $35(46.7 \%)$ of the community controls had skin test induration $\geq 10 \mathrm{~mm}$. Moreover, $44(91.7 \%)$ PTB patients, 58 $(65.9 \%)$ of the household contacts and $26(34.7 \%)$ of the community controls had skin test induration $\geq 15 \mathrm{~mm}$, respectively. The mean size of TST induration was significantly higher in TB patients $(18.1 \mathrm{~mm})$ compared to that of household contacts $(13.6 \mathrm{~mm})$ and community controls $(7.9$ $\mathrm{mm})(\mathrm{p}<0.001)$. Conclusion: Skin test induration $\geq 15 \mathrm{~mm}$ seems to be optimal for suspecting active TB and recommending chest X-ray for migrants from Ethiopia, and other sub-Saharan countries, while skin test induration $\geq 10 \mathrm{~mm}$ seems optimal to suggest $M t b$ infection.

"Corresponding author. 


\section{Keywords}

\section{Tuberculosis; TST; Diagnosis; IGRA; Migrant; Ethiopia; HIV}

\section{Background}

Globally, it is estimated that more than two billion people are $M t b$ infected [1]. Early diagnosis and treatment are crucial to reduce TB transmission, morbidity and mortality. In addition, identification of persons with latent TB infection, especially those who are at higher risk of progression to active disease, and use of preventive treatment is necessary to reduce the burden of TB.

Interferon Gamma Release Assays (IGRAs) and TST are two tests currently used for screening latent TB infection and also aid for the diagnosis of active TB. IGRAs do not detect the actual TB bacilli, but instead they assess cellular production of interferon gamma (IFN- $\gamma$ ) in response to Mtb specific antigens, which have no/less cross reactivity with BCG vaccination and non-tuberculosis mycobacterial (NTM) infections. Many countries in the world still rely on the TST for the identification of latent TB infection [2], especially western countries are still using TST for screening of latent TB among migrant people from the high TB endemic countries [3]-[5]. TST measures cellular immune responses against exposure to mycobacteria infections, following the injection of tuberculin and the reaction usually begins 5 to 6 hours later though maximal indurations takes place at 48 to 72 hours, and subsides over a period of days [6]. However, interpretation of the test result is based on risk categories [6], and different cut-off values have been recommended for defining a positive TST with different clinical situations. A cut-off value ( $\geq 10 \mathrm{~mm}$ ), recommended by the World Health Organization (WHO) [6] would otherwise remain a useful criterion for TST positivity. Higher cut-off values ( $\geq 15 \mathrm{~mm}$ ) show higher chance of TB infection [7], but this is not always true [3] [8]-[11].

Considering the effect of environmental mycobacterium and BCG vaccination in most developing countries, including Ethiopia, the cut-off point recommended by WHO for screening of TB infection requires re-assessment, and this study was designed to compare the size of skin test induration in smear positive TB patients, their household contacts and community controls, and to optimize the cut-off points for the diagnosis of TB.

\section{Methods}

\subsection{Study Area and Population}

A health facility-based cross-sectional study was conducted in Addis Ababa, the capital city of Ethiopia between June 2012 and October 2012. The city has an estimated population of 3.5 million according to population census of 2007 [12]. HIV/AIDS and TB are among the major public health problems of the inhabitants of Addis Ababa [13]. In Addis Ababa, all health centers offer anti-TB treatment to TB patients. Based on the number of TB patients, six health centers were purposely selected for the present study.

All PTB suspects who came to the selected health facilities, household contacts of TB index cases and community controls from the same area were part of the source population. Study participants were selected from the source population if they were smear positive PTB patients (for TB patients), if they were household contacts of TB index cases (for household contacts), if they had no history of TB or history of contact with known TB patients (for community controls), age above 15 years (for all participants) and voluntarily agreed to participate in the study. Smear negative and extra PTB patients, pregnant women, seriously sick patients, HIV infected individuals, individuals who were on immunosuppressive drugs and individuals who had chronic medical illness such as diabetes and cancer were not included in this study.

\subsection{Data Collection}

Patients who were suspected of PTB and visited the selected health facilities were clinically examined, sputum samples (spot-morning-spot) were collected, processed using the Ziehl-Neelsen (ZN) staining method and examined microscopically for acid fast bacilli (AFB) at the respective health facility by an experienced laboratory technician. A minimum of 100 oil immersion fields were examined before a negative result was declared. Patients were also screened using TST (Tuberculin PPD RT23, Statens Serum Institute, Copenhagen, Denmark) 
and QFTGIT (QuantiFERON ${ }^{\circledR}$-TB Gold In-Tube, Cellestis Ltd., Carnegie, Australia) following procedures used by previous study [14], and according to the manufacturers' instructions. Household contacts of PTB patients and community controls were screened for TB infection using questionnaires, TST and QFT-GIT.

In addition, chest X-ray was done in household contacts and community controls whose skin test induration was $\geq 10 \mathrm{~mm}$. Data such as anthropometric data (body mass index, BMI), HIV infection and BCG vaccination were also collected. The presence of BCG scar was considered as the criteria for deciding the vaccination status.

In order to measure and compare the mean values of TST in smear positive PTB patients, their contacts and community controls it was estimated to recruit a total number of 78 eligible smear positive PTB patients, 78 close contacts and 78 community controls by assuming a mean diameter induration and standard deviation of $16.8 \pm 3.8 \mathrm{~mm}$ among smear positive TB patients [15] and a mean diameter induration and standard deviation of $13.0 \pm 11.29 \mathrm{~mm}$ among household contacts [16], while assuming a test power of $80 \%$ and $95 \%$ confidence interval.

\subsection{Ethical Consideration}

The study was ethically approved by the Norwegian Regional Committe for Southeast (Regionale Komite for Medisink og Helsefaglig forskningsetikk, REK, Sør-Øst) the Institutional Review Board of the Aklilu Lemma Institute of Pathobiology, and the National Research Ethics Review Committee of Ethiopian Science and Technology Ministry. Participants of this study were informed about the purpose of the study as well as risks and benefits associated with it before they gave their consent. Care has been taken during tuberculin PPD injection and blood collection. Individuals who had sign/symptoms of active TB and those whose skin test induration $\geq 10$ $\mathrm{mm}$ have undergone further investigation for TB. All participants were offered provider initiated HIV counseling and testing. Both counseling and testing were done confidentially by health workers who were working at the respective health facility and responsible for HIV counseling and testing of TB patients.

\subsection{Data Analysis}

Data were entered into epidata version 3.1 and analyzed using Stata version 11. Agreement between TST and QFTGIT was assessed using Cohen's Kappa (K) coefficient. Odds ratio and 95\% confidence intervals obtained from logistic regression analysis were used to assess the strength of association of participants' background characteristics with the likelihood of having positive TST or QFTGIT. Two-sample t-test was used to compare the mean skin test induration and levels of interferon gamma among subgroups of study participants (two groups at a time). Chi-square test was used to compare proportion. A p-value $<0.05$ was considered statistically significant for each statistical test performed.

\section{Results}

\subsection{Baseline Characteristics of Study Participants}

Out of 250 individuals (110 males and 114 females) invited to participate in this study, 26 (13 males and 13 females) were excluded because of pre-specified exclusion criteria such as HIV, diabetes, pregnancy, and previous history of TB. Two participants from household contacts were diagnosed as having TB during the study period and they started on anti-TB treatment. Hence, this paper is based on the data generated from a total of 224 participants (50 PTB patients, 96 household contacts and 78 community controls).

The mean age was 31.1 years for PTB Patients, 32.4 years for household contacts, and 32.6 years for community controls, whereas the median ages for the respective subgroups were 24.5 years, 28 years and 30 years. The majority (85\%) of the study participants are literate.

The baseline characteristics like BCG status, nutritional status, smoking and alcohol consumption of the participants are summarized in Table 1. Half (50\%) of the patients, $18.8 \%$ of the household contacts and $6.4 \%$ of the community controls were underweight (BMI $<18.5 \mathrm{~kg} / \mathrm{m}^{2}$ ). More than $30 \%$ of the study participants reported use of at least one of the three substances, namely, cigarette, khat and alcohol.

\subsection{TST and QFTGIT Results}

Table 2 shows the results of TST and QFTGIT in PTB patients, household contacts and community controls. 
Table 1. Baseline characteristics of the study participants.

\begin{tabular}{|c|c|c|c|c|c|}
\hline Baseline characteristics & $\begin{array}{c}\text { Total } \\
\text { Number (\%) }\end{array}$ & $\begin{array}{c}\text { Patients } \\
\text { Number (\%) }\end{array}$ & $\begin{array}{c}\text { Contacts } \\
\text { Number (\%) }\end{array}$ & $\begin{array}{c}\text { Controls } \\
\text { Number (\%) }\end{array}$ & p-value \\
\hline \multicolumn{6}{|l|}{ BCG scar } \\
\hline Yes & 89 (39.7) & $12(24.0)$ & $44(45.8)$ & $33(42.3)$ & \multirow{3}{*}{0.021} \\
\hline No & $113(50.5)$ & $33(66.0)$ & $39(40.3)$ & $41(52.6)$ & \\
\hline Indeterminate & $22(9.8)$ & $5(10.0)$ & 13 (13.5) & $4(5.1)$ & \\
\hline \multicolumn{6}{|l|}{$\mathrm{BMI}$ in $\mathrm{Kg} / \mathrm{m}^{2}$} \\
\hline$<18.5$ & $48(21.4)$ & $25(50.0)$ & $18(18.8)$ & $5(6.4)$ & \multirow{3}{*}{$<0.001$} \\
\hline $18.5-24.99$ & $148(66.1)$ & $24(48.0)$ & $71(74.0)$ & $53(68.0)$ & \\
\hline$\geq 25$ & $28(12.5)$ & $1(2.0)$ & $7(7.3)$ & $20(25.6)$ & \\
\hline \multicolumn{6}{|l|}{ Alcohol consumption } \\
\hline Yes & $72(35.1)$ & $13(30.2)$ & $32(37.6)$ & $27(35.1)$ & \multirow[t]{2}{*}{0.709} \\
\hline No & 133 (64.9) & $30(69.8)$ & $53(62.4)$ & $50(64.9)$ & \\
\hline \multicolumn{6}{|l|}{ Smoking } \\
\hline Yes & $24(11.7)$ & $8(18.6)$ & $12(14.1)$ & $4(5.2)$ & \multirow[t]{2}{*}{0.060} \\
\hline No & $181(88.3)$ & 35 (81.4) & 73 (85.9) & $73(94.8)$ & \\
\hline \multicolumn{6}{|l|}{ Chewing khat } \\
\hline Yes & $32(15.8)$ & $10(23.3)$ & $12(14.1)$ & $10(13.0)$ & \multirow[t]{2}{*}{0.293} \\
\hline No & $171(84.2)$ & $33(76.7)$ & $73(85.9)$ & $67(87.0)$ & \\
\hline
\end{tabular}

Table 2. Results of TST and QFTGIT test in the three groups study participants.

\begin{tabular}{|c|c|c|c|}
\hline Test and cut-off point & Patients Number (\%) & Contacts Number (\%) & Controls Number (\%) \\
\hline \multicolumn{4}{|l|}{ TST in $\mathbf{m m}$} \\
\hline$<10 \mathrm{~mm}$ & $0(0.0)$ & $24(27.3)$ & $40(53.3)$ \\
\hline$\geq 10$ and $<15 \mathrm{~mm}$ & $4(8.3)$ & $6(6.8)$ & $9(12.0)$ \\
\hline$\geq 15 \mathrm{~mm}$ & 44 (91.7) & 58 (65.9) & $26(34.7)$ \\
\hline \multicolumn{4}{|l|}{ IFN- $\gamma$ level (IU/ml) } \\
\hline$\geq 0.35 \mathrm{IU} / \mathrm{ml}$ & $36(81.8)$ & $64(70.3)$ & $32(55.2)$ \\
\hline$<0.35 \mathrm{IU} / \mathrm{ml}$ & 8 (18.2) & 27 (29.7) & $26(44.8)$ \\
\hline
\end{tabular}

Forty eight PTB patients, 88 household contacts and 75 community controls had TST results, whereas 44 PTB patients, 91 household contacts and 58 community controls had QFTGIT results. At the cut-off point of TST $\geq$ $10 \mathrm{~mm}, 72.7 \%$ (95\% CI: 62.2, 81.7) of the household contacts were positive for Mtb infection, while the positivity was 46.7\% (95\% CI: 35.1, 58.6) among community controls. All smear positive PTB patients had skin test induration $>10 \mathrm{~mm}$. Twelve of the household contacts (13.6\%) and 33 (44\%) of the community controls had no skin test induration. The percentage of TST distribution for each subgroup is summarized in Figures 1(a)-(c).

In community controls, the proportion of TST positivity was higher in males compared to females $(61.3 \%$ versus $\left.36.4 \%, \mathrm{x}^{2}=4.5402, \mathrm{p}=0.033\right)$. The proportion of TST positivity was not significantly different across age categories both in household contacts $\left(x^{2}=0.5246, p=0.769\right)$ and community controls $\left(x^{2}=5.6767, p=\right.$ 0.059). Similarly, nutritional status and use of substances (cigarette, khat and alcohol) did not have significant effect on TST both in household contacts and in community controls. However, the proportion of TST positivity was significantly higher in individuals who had BCG scar compared to individuals who had no BCG scar, or indeterminate cases (89.7\% vs. 50.0\%, $\left.\mathrm{x}^{2}=15.9947, \mathrm{p}<0.001\right)$.

The mean size of TST induration was significantly higher in smear positive PTB patients (18.1 mm) compared to that of household contacts $(13.6 \mathrm{~mm})$ and community controls $(7.9 \mathrm{~mm})(\mathrm{p}<0.001)$. Similarly, there was a significant difference between the mean values of TST in household contacts and community controls (p < 


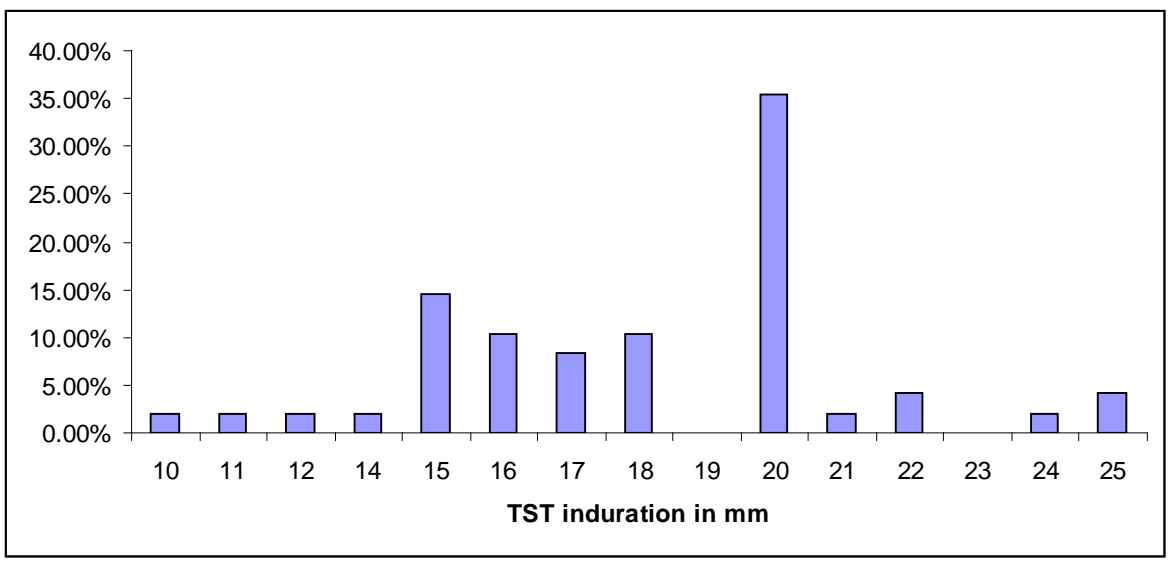

(a)

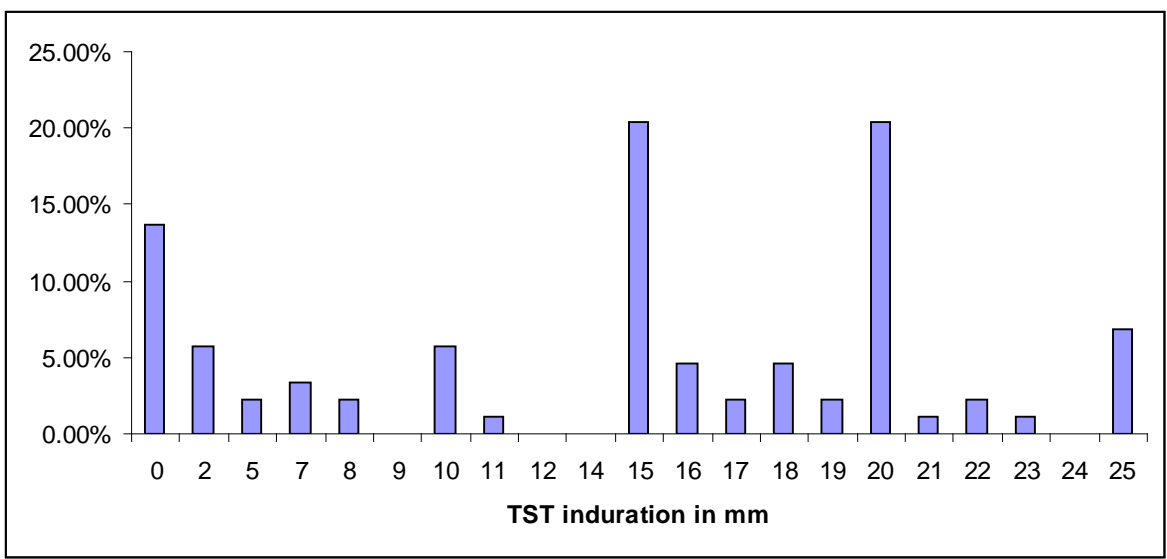

(b)

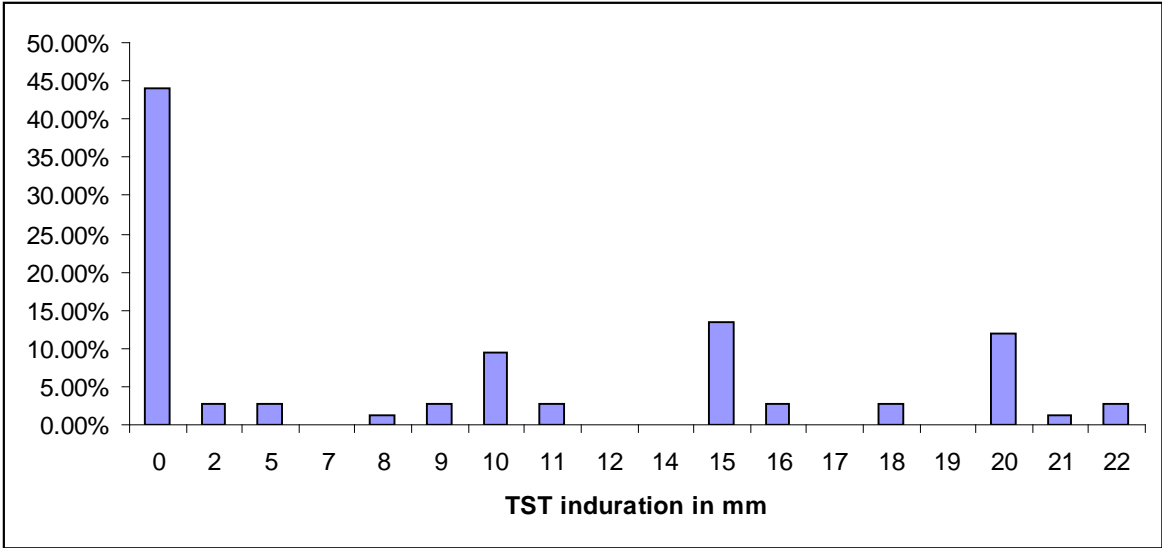

(c)

Figure 1. (a) TST distribution in smear positive PTB patients; (b) TST distribution in household contacts; (c) TST distribution in community controls.

0.001). There was no significance difference between the mean of skin test induration size in males and females in smear positive PTB patients $(17.9 \mathrm{~mm}$ vs. $18.4 \mathrm{~mm} \mathrm{p}=0.6527)$ and in household contacts $(14.1 \mathrm{~mm}$ vs. 13.0 $\mathrm{mm}, \mathrm{p}=0.5007)$. However, the mean size of skin test induration in males was higher than that of females in community controls $(10.5 \mathrm{~mm}$ versus $6.0 \mathrm{~mm}, \mathrm{p}=0.0146)$. The mean size of skin test induration was not significantly affected by age categories $(\mathrm{p}>0.05)$ in all subgroups. The mean size of skin test induration size was higher in individuals who had BMI value $>18.5 \mathrm{~kg} / \mathrm{m}^{2}$ compared to individuals who had BMI $<18.5 \mathrm{~kg} / \mathrm{m}^{2}$ in 
smear positive PTB patients (19.1 mm vs. $17.1 \mathrm{~mm}, \mathrm{p}=0.0276)$. The mean size of skin test induration did not differ in contacts and community controls by BMI status of the individuals $(p>0.05)$. The mean size of skin test induration was higher in individuals who had BCG scar compared to individuals without BCG scar in household contacts $(\mathrm{F}=6.8, \mathrm{p}=0.0018)$. Considering all participants as whole, the mean difference of TST in BCG vaccinated and non-BCG vaccinated participants was statistically significant $(\mathrm{p}=0.0136)$.

Results of OFTGIT indicate that at the cut-off point $\geq 0.35 \mathrm{IU} / \mathrm{ml}$ of IFN- $\gamma, 81.8 \%$ (95\% CI: 67.3, 91.8), 70.3\% (95\% CI: 59.2, 80.0) and 55.2\% (95\% CI: 41.5, 68.3) of the PTB patients, household contacts and community controls, respectively were positive for $M t b$ infection. The mean level of IFN- $\gamma$ was $4.68 \mathrm{IU} / \mathrm{ml}$ in smear positive PTB patients, $4.90 \mathrm{IU} / \mathrm{ml}$ in contacts and $2.62 \mathrm{IU} / \mathrm{ml}$ in community controls. There was a significant difference between the mean level of IFN- $\gamma$ in smear positive PTB patients and community controls as well as in household contacts and community controls $(\mathrm{p}<0.05)$. The mean level of IFN- $\gamma$ and proportion of QFTGIT positivity did not differ by gender, age categories, BCG scar, BMI status, or use of substances (cigarette, khat and alcohol) in smear positive PTB patients, in contacts and in community controls ( $\mathrm{p}>0.05)$. However, the mean level of IFN- $\gamma$ was significantly higher in individuals who had skin test induration $\geq 10 \mathrm{~mm}$ compared to those individuals who had skin test induration $<10 \mathrm{~mm}$ in subgroups (Figures 2(a)-(c)).

\subsection{Association of Background Characteristics of Participants with TST and QFTGIT Positivity}

Using a logistic regression, the association of background characteristics of study participants with TST and QFTGIT positivity has been assessed (Tables 3 \& 4). Being a female participant was significantly associated

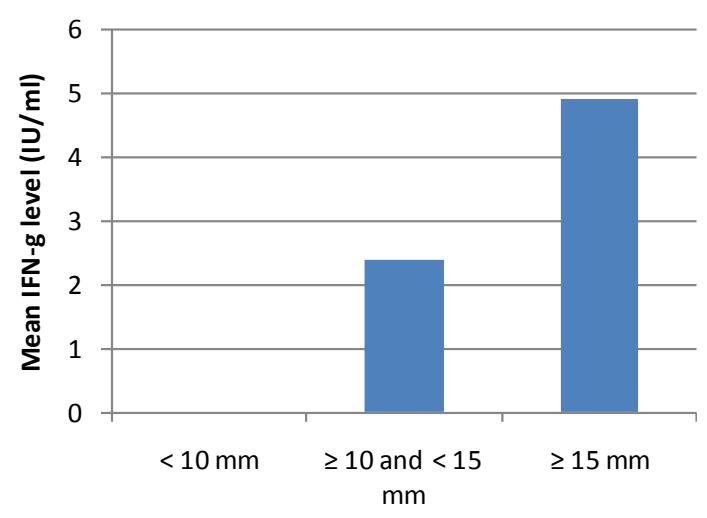

Skin test induration in $\mathrm{mm}$

(a)

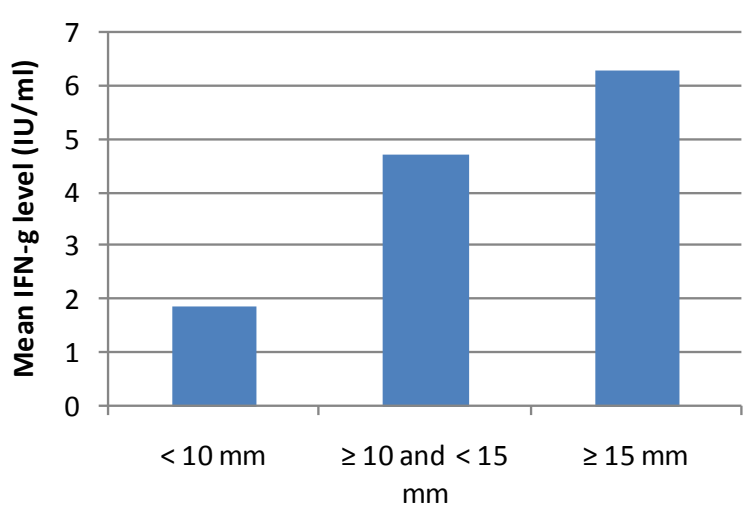

Skin test induration in $\mathrm{mm}$

(b)

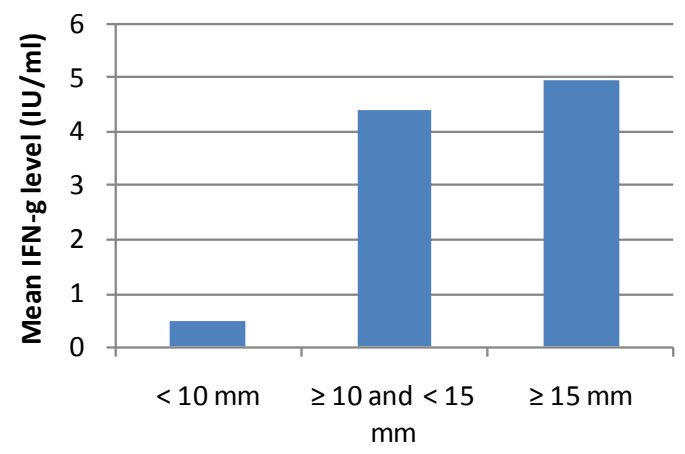

Skin test induration in $\mathrm{mm}$

(c)

Figure 2. (a) The mean level of IFN- $\gamma$ in smear positive PTB patients in relation to skin test induration; (b) The mean level of IFN- $\gamma$ in household contacts in relation to skin test induration; (c) The mean level of IFN- $\gamma$ in community controls in relation to skin test induration. 
Table 3. Association of baseline characteristics of the study participants with TST positivity in household contacts.

\begin{tabular}{|c|c|c|c|}
\hline Baseline characteristics & $\begin{array}{c}\text { Contacts } \\
\text { Number(\%) positive }\end{array}$ & COR $(95 \% \mathrm{CI})$ & AOR (95\% CI) \\
\hline \multicolumn{4}{|l|}{ Sex } \\
\hline Male & $36(78.3)$ & Reference & \\
\hline Female & $28(66.7)$ & $0.56(0.21-1.43)$ & \\
\hline \multicolumn{4}{|l|}{ Age } \\
\hline $15-30$ & $38(70.4)$ & Reference & \\
\hline $31-45$ & 15 (78.9) & $1.58(0.45-5.50)$ & \\
\hline$>45$ & $11(73.3)$ & $1.16(0.32-4.18)$ & \\
\hline \multicolumn{4}{|l|}{ BCG scar } \\
\hline Yes & 35 (89.7) & Reference & Reference \\
\hline No & $18(50.0)$ & $0.11(0.03-0.39)$ & $0.09(0.02-0.46)$ \\
\hline Indeterminate & $11(84.6)$ & $0.63(0.10-3.91)$ & $0.31(0.03-3.12)$ \\
\hline \multicolumn{4}{|l|}{ BMI in $\mathrm{Kg} / \mathrm{m}^{2}$} \\
\hline$<18.5$ & $14(82.4)$ & Reference & \\
\hline $18.5-24.99$ & $46(69.7)$ & $0.49(0.13-1.91)$ & \\
\hline$\geq 25$ & $4(80.0)$ & $0.86(0.07-10.67)$ & \\
\hline \multicolumn{4}{|l|}{ Alcohol consumption } \\
\hline Yes & $23(79.3)$ & Reference & \\
\hline No & $34(69.4)$ & $0.59(0.19-1.75)$ & \\
\hline \multicolumn{4}{|l|}{ Smoking } \\
\hline Yes & $10(90.9)$ & Reference & \\
\hline No & $47(70.2)$ & $0.24(0.03-1.96)$ & \\
\hline \multicolumn{4}{|l|}{ Chewing khat } \\
\hline Yes & $9(81.8)$ & Reference & \\
\hline No & $48(71.6)$ & $0.56(0.11-2.84)$ & \\
\hline \multicolumn{4}{|l|}{ IFN-g level (IU/ml) } \\
\hline$\geq 0.35$ & $55(91.7)$ & Reference & Reference \\
\hline$<0.35$ & $8(32.0)$ & $0.04(0.01-0.15)$ & $0.03(0.01-0.15)$ \\
\hline
\end{tabular}

$\mathrm{COR}=$ crude odds ratio, $\mathrm{AOR}=$ adjusted odds ratio.

with low skin test positivity in community controls (crude odds ratio $=0.36,95 \% \mathrm{CI}, 0.14$ to $0.93, \mathrm{p}=0.035$ ). On the other hand, age group between 31 - 45 years was significantly associated with TST positivity in community controls (crude odds ratio $=3.33,95 \%$ CI, 1.15 to 9.65, $\mathrm{p}=0.026$ ). Lack of BCG scar was significantly associated with low TST positivity in contacts (adjusted odds ratio $=0.09,95 \% \mathrm{CI}, 0.02$ to $0.46, \mathrm{p}=0.001$ ). TST negativity was significantly associated with QFTGIT negativity both in contacts (adjusted odds ratio $=0.03$, 95\% CI, 0.01 to $0.15, \mathrm{p}<0.001$ ) (Table 3 ) and in community controls (adjusted odds ratio $=0.02,95 \% \mathrm{CI}, 0.00$ to $0.12, \mathrm{p}<0.001$ ) (Table 4).

Apart from TST, none of the background characteristics was associated with QFTGIT positivity. There was strong association of QFTGIT positivity with TST $\geq 10 \mathrm{~mm}$ in contacts (crude odds ratio $=23.4,95 \%$ CI, 6.8 to 81.0, $\mathrm{p}<0.001$ ) and in community controls (crude odds ratio $=33.2,95 \% \mathrm{CI}, 7.5$ to $148.2, \mathrm{p}<0.001$ ).

\subsection{Agreement between TST and QFTGIT Test Results}

Out of 224 participants, 211 (94.2\%) were tested by TST, 193 (86.2\%) were tested by QFTGIT and 187 (83.5\%) were tested by both tests. At the cut-off point $\geq 10 \mathrm{~mm}$ for TST, $136(72.73 \%)$ of the study participants were positive by TST and at the cut-off point $\geq 0.35 \mathrm{IU} / \mathrm{ml}$ of IFN- $\gamma, 128$ (68.50\%) of the participants were positive 
Table 4. Association of baseline characteristics of the study participants with TST positivity in community controls.

\begin{tabular}{|c|c|c|c|}
\hline Baseline characteristics & $\begin{array}{c}\text { Controls } \\
\text { Number (\%). positive }\end{array}$ & COR, $(95 \%$ CI) & AOR, (95\% CI) \\
\hline \multicolumn{4}{|l|}{ Sex } \\
\hline Male & $19(61.3)$ & Reference & Reference \\
\hline Female & $16(36.4)$ & $0.36(0.14-0.93)$ & $0.22(0.02-2.31)$ \\
\hline \multicolumn{4}{|l|}{ Age } \\
\hline $15-30$ & $15(37.5)$ & Reference & Reference \\
\hline $31-45$ & $16(66.7)$ & $3.33(1.15-9.65)$ & $9.04(0.76-107.99)$ \\
\hline$>45$ & $4(36.4)$ & $0.95(0.24-3.81)$ & $1.63(0.08-31.63)$ \\
\hline \multicolumn{4}{|l|}{ BCG scar } \\
\hline Yes & $20(60.6)$ & Reference & Reference \\
\hline No & $14(36.8)$ & $0.38(0.15-0.99)$ & $0.23(0.03-1.63)$ \\
\hline Indeterminate & $1(25.0)$ & $0.22(0.20-2.31)$ & Omitted \\
\hline \multicolumn{4}{|l|}{$\mathrm{BMI}$ in $\mathrm{Kg} / \mathbf{m}^{2}$} \\
\hline$<18.5$ & $2(40.0)$ & Reference & \\
\hline $18.5-24.99$ & $22(42.3)$ & $1.1(0.17-7.15)$ & \\
\hline$\geq 25$ & $11(61.1)$ & $2.36(0.31-17.85)$ & \\
\hline \multicolumn{4}{|l|}{ Alcohol consumption } \\
\hline Yes & $11(40.7)$ & Reference & \\
\hline No & $24(48)$ & $1.22(0.46-3.22)$ & \\
\hline \multicolumn{4}{|l|}{ Smoking } \\
\hline Yes & $4(100.0 \%)$ & Omitted & \\
\hline No & $31(44.3)$ & $\ldots \ldots \ldots \ldots$ & \\
\hline \multicolumn{4}{|l|}{ Chewing khat } \\
\hline Yes & $7(70.0)$ & Reference & \\
\hline No & $28(43.8)$ & $0.33(0.08-1.41)$ & \\
\hline \multicolumn{4}{|l|}{ IFN-g level (IU/ml) } \\
\hline$\geq 0.35$ & $26(81.3)$ & Reference & Reference \\
\hline$<0.35$ & 3 (11.5) & $0.03(0.01-0.13)$ & $0.02(0.00-0.12)$ \\
\hline
\end{tabular}

by QFTGIT. However, 117 (62.6\%) of the participants tested positive for both tests, whereas 40 (21.4\%) of the participants were negative for both tests. There were 19 (10.2\%) participants who tested positive by TST, but negative by QFTGIT, and on the other hand, there were 11 (5.9\%) participants who tested positive by QFTGIT, but negative by TST (Table 5).

There was good overall agreement between the two tests (percent agreement $=83.9 \%$; $k$ appa $=0.6145$ ). Similarly, the agreement between the two tests was good for household contacts (percent agreement $=84.7 \%$, kappa $=0.6183$ ) and community controls (percent agreement $=84.5 \%$, kappa $=0.6897$ ). Out of 44 smear positive PTB patients who had positive skin test, 8 individuals (18.2\%) were negative by TB-gold.

\section{Discussion}

Tuberculin skin test (TST), that measures cellular immune response against exposure to $M t b$ antigens, has been widely used for the screening of latent TB and as an aid for the diagnosis of active TB in the developed world. Based on the recommendations of WHO and CDC [6] skin induration of $\geq 10 \mathrm{~mm}$ is considered positive for Mtb infection and/or clinical TB. However, although TST positivity may be affected by local socio-economic, environmental, genetic and nutritional status of the population, no studies have been conducted in many sub-Saharan Africa, including Ethiopia, to assess the validity of this cut-off point. This study was designed to compare the 
Table 5. Agreement between TST at the cut-off point $\geq 10 \mathrm{~mm}$ of skin induration and QFTGIT at the cut-off point $\geq 0.35$ $\mathrm{IU} / \mathrm{ml}$ level of IFN $-\gamma$ for all participants.

\begin{tabular}{cccc}
\hline \multirow{2}{*}{ QFTGIT } & \multicolumn{2}{c}{ TST } & Total \\
\cline { 2 - 3 }$\geq 0.35 \mathrm{IU} / \mathrm{ml}$ & $\geq 10 \mathrm{~mm}$ & $11(5.9 \%)$ & $128(68.5 \%)$ \\
$<0.35 \mathrm{IU} / \mathrm{ml}$ & $117(62.6 \%)$ & $40(21.4 \%)$ & $59(31.6 \%)$ \\
Total & $19(10.2 \%)$ & $51(27.3 \%)$ & 187 \\
\hline
\end{tabular}

skin test induration among smear positive PTB patients, their household contacts and community controls in Ethiopia to suggest the optimal cut-off points for $M t b$ infection and clinical TB. The results indicated that all smear positive PTB patients had skin test induration $\geq 10 \mathrm{~mm}$ with mean skin test induration of $18.1 \mathrm{~mm}$, while the majority $(77 \%)$ had skin test induration $\geq 15 \mathrm{~mm}$. The results of this study also showed that the majority (72.7\%) of the household contacts (i.e. the high risk group) had skin test induration $\geq 10 \mathrm{~mm}$, while the mean skin test induration was $13.6 \mathrm{~mm}$. Relatively, small proportion (46.7\%) of the community controls (i.e. the low risk group) had skin test induration $\geq 10 \mathrm{~mm}$, while the mean skin test induration was $7.9 \mathrm{~mm}$. Taken together, the findings of the present study suggest that TST induration $\geq 10 \mathrm{~mm}$ and $\geq 15 \mathrm{~mm}$ would safely discriminate between $M t b$ infection and clinical TB which is in agreement with the recommendation of WHO and CDC [6] that TST skin induration $\geq 10 \mathrm{~mm}$ be used as a cut-off point to identify latently infected cases. Study by Vekemans et al. [17] in the Gambia showed high prevalence of TST positivity in TB patients (93\%) and household contacts (86\%) compared to community controls (38\%). Cobelens et al. [15] also reported a mean skin test induration of $16.8 \mathrm{~mm}$ in smear positive TB patients, while Lao and De Guia [16] reported a mean skin test induration of $13.0 \mathrm{~mm}$ among household contacts.

In the present study, it was observed that relatively higher proportion of the community controls (44\%) had no measureable skin test induration (i.e. $0 \mathrm{~mm}$ ) compared to that of household contacts (13.6\%). Previous studies showed that non-responsiveness of the skin test could occur because of some chronic medical illness like diabetes mellitus, cancer, infectious diseases like HIV/AIDS, parasites, or malnutrition, technical problems, or the absence of $M t b$ infection [18] [19]. However, the high proportion of $0 \mathrm{~mm}$ skin test induration observed in the community controls most likely indicates the absence of infection with Mtb. A study by Lienhardt et al. [20] in the Gambia showed higher proportion of $0 \mathrm{~mm}$ skin test induration in community controls compared to household contacts of smear positive TB patients. Study by Kang et al. [21] in Korea also showed higher proportion of $0 \mathrm{~mm}$ skin test induration in individuals who did not report known contacts with TB patients compared to household contacts of smear positive TB patients. A high proportion (48\%) of anergy was reported in a recent community-based study of latent TB infection in Ethiopia [14].

In the present study, the prevalence of $M t b$ infection among the household contacts and community controls were $70.3 \%$ and $55.2 \%$ using QFTGIT respectively. These results were comparable with the results of TST in both cases. However, $8(18.2 \%)$ smear positive TB patients who had skin test induration $\geq 10 \mathrm{~mm}$ were found to be negative by QFTGIT. Although the reason has not been investigated, previous study in Ethiopia also showed high false negativity rate of the test in culture and/or smear positive PTB patients [22]. False negative results related to IGRAs have been also reported in several previous studies [23]-[25] On the other hand, there was a positive trend between the mean levels of IFN- induced by the specific antigens and the skin induration size of the study participants in all groups which is similar to the findings of previous studies in Ethiopia [26] [27]. The rate of positivity was also significantly associated with an increasing size of TST induration which is similar to the findings of studies in Ethiopia [14] and in Korean [28]. Furthermore, there was a good agreement between the two tests in household contacts and community controls. This finding is similar with the findings of the study conducted in Addis Ababa, Ethiopia [26], while it is inconsistent in other study conducted in Afar Region, Ethiopia [14].

In the present study, $50 \%$ of PTB patients were underweight $\left(B M I<18.5 \mathrm{~kg} / \mathrm{m}^{2}\right)$. Similarly, several previous studies have been shown that malnutrition profoundly affects the host defense against TB and even, malnutrition may account for a greater population attributable risk of TB than HIV infection [29] [30]. Malnutrition was also associated with a high risk for early mortality in TB patients, delay in bacterial clearance during the course of anti-TB treatment and the spreading of MDR-TB [30]-[32]. Thus, malnutrition should also be given more attention in line with the prevention of HIV/AIDS in the fight against TB in Ethiopia. 
One major strength of the current study is that three groups (sputum smear positive TB patients, their house contacts and community controls) were compared to re-assess the size of skin induration and cut-off point for latent infection using TST. However, although the average skin induration for community controls was $7.9 \mathrm{~mm}$, some community controls also had skin induration of $>10 \mathrm{~mm}$. This makes it difficult to rule out the possibility that some of the community controls could be $M t b$ infected. Secondly, although the study sample is large enough to make statistical analysis, it may not be enough to make sound conclusions. Therefore, a further study on similar study groups but with a larger sample size in another high endemic setting is required to make sound conclusions.

\section{Conclusion}

TST is the standard tool to detect latent TB infection in many developed countries, and TST skin induration of $\geq 10 \mathrm{~mm}$ is the cut-off point to discriminate infection from non-infection. Results of the present study are in agreement with the TST cut-off point recommended by WHO and CDC to discriminate between Mtb infection and non-infection. Moreover, both TST and QFTGIT showed more or less similar diagnostic performance in demonstrating of $M t b$ infection. The majority (91.7\%) of smear positive TB patients had skin test induration $\geq$ $15 \mathrm{~mm}$. Moreover, the specificity of the TST was found to be $100 \%$ at skin test induration $\geq 15 \mathrm{~mm}$ in community controls who had no known exposure to TB. Since, a test with high specificity is more useful in areas with a high prevalence of disease, skin test induration $\geq 15 \mathrm{~mm}$ seems to be optimal for suspecting active TB and recommending chest $\mathrm{X}$-ray in individuals without symptoms suggestive of active TB, while skin test induration $\geq$ $10 \mathrm{~mm}$ seems optimal to suggest Mtb infection in household contacts of TB patients.

\section{Acknowledgements}

We would like to thank University of Oslo, Department of Community Medicine for financial assistance, Aklilu Lemma Institute of Patho-Biology (ALIPB) for facilitating our field and laboratory work, and Armuer Hansen Research Institute (AHRI) for access to and assistance in the laboratory work. .Our special thanks go also to all participants of this study for their willingness to participate in the study. Nurses who have been working at TB clinics of the study sites deserve deep acknowledgment for their unreserved cooperation during data collection. We would like to thank the staff of ALIPB, Mrs Mahlet Chaniyalew and Ato Hailu Getu for their assistance both in the field and laboratory. We would like to thank nurse Gezahegn Getachew staff of Melka Werer Health Centre for his technical assistance during tuberculin skin test.

\section{Authors' Contributions}

KC designed the study, participated in data collection, analysis and drafted the manuscript. ML participated in study design, data collection, analysis and write-up. MB participated in data collection and write-up. GMD participated in study design, data analysis/interpretation and write-up. GB involved in study design and write-up of manuscript. FA developed the idea and participated in the study design, data analysis and write-up of the manuscript and critically revised the manuscript. All authors read and approved the final manuscript. FA is a corresponding author.

\section{Competing Interests}

The authors declare that they have no competing interests.

\section{References}

[1] World Health Organization (2008) Global Tuberculosis Control: Surveillance, Planning, Financing. WHO Report 2008, Geneva.

[2] Winje, B.A. (2008) Comparison of QuantiFERON TB Gold with Tuberculin Skin Test to Improve Diagnostics and Routine Screening for Tuberculosis Infection among Newly Arrived Asylum Seekers to Norway.

[3] WHO (2011) Tuberculosis. IGRA TB Tests, Policy Statement 2011, WHO.

[4] Harstad, I., Heldal, E., Steinshamn, S.L., Garåsen, H. and Jacobsen, G.W. (2009) Tuberculosis Screening and Follow-Up of Asylum Seekers in Norway: ACohort Study. BMC Public Health, 9, 141. http://dx.doi.org/10.1186/1471-2458-9-141 
[5] Parenti, D.M., Lucas, D., Lee, A. and Hollenkamp, R.H. (1987) Health Status of Ethiopian Refugees in the United States. AJPH, 77, 12-59.

[6] American Thoracic Society and CDC (2000) Diagnostic Standards and Classification of Tuberculosis in Adults and Children. American Journal of Respiratory and Critical Care Medicine, 161, 1376-1395. http://dx.doi.org/10.1164/ajrccm.161.4.16141

[7] Wang, L., Turner, M.O., Elwood, R.K., et al. (2002) A Metanalysis of the Effect of BacilleCalmette Guerin Vaccination on Tuberculin Skin Test Measurements. Thorax, 57, 804-809. http://dx.doi.org/10.1136/thorax.57.9.804

[8] Menzies, R.I., Reichman, L.B. and Herschfield, E. (2000) Tuberculin Skin Testing. In: Reichman, L.B. and Hershfield, E.S., Eds., Tuberculosis, Marcel Dekker, New York, 279-322.

[9] Martin, P. (2003) Mantoux Testing. Guidelines for Tuberculosis Control in New Zealand.

[10] Watkins, R.E., Brennan, R. and Plant, A.J. (2004) Tuberculin Reactivity and the Risk of Tuberculosis: Review. International Journal of Tuberculosis and Lung Disease, 4, 895-903.

[11] Al Zahrani, K., Al Jahdali, H. and Menzies, D. (2000) Does Size Matter? Utility of Size of Tuberculin Reactions for the Diagnosis of Mycobacterial Disease. American Journal of Respiratory and Critical Care Medicine, 162, 1419-1422. http://dx.doi.org/10.1164/ajrccm.162.4.9912048

[12] Central Statistics Agency (2007) Population and Housing Census of Ethiopia.

[13] Federal Ministry of Health (2010) Annual Health Service Report. Addis Ababa, Ethiopia.

[14] Legesse, M., Ameni, G., Mamo, G., Medhin, G., Bjune, G. and Abebe, F. (2011) Community-Based Cross-Sectional Survey of Latent Tuberculosis Infection in Afar Pastoralists, Ethiopia, Using QuantiFERON-TB Gold In-Tubeand Tuberculin Skin Test. BMC Infectious Diseases, 11, 89. http://dx.doi.org/10.1186/1471-2334-11-89

[15] Cobelens, F.G., Egwaga, S.M., van Ginkel, T., Muwinge, H., Matee, M.I. and Borgdorff, M.W. (2006) Tuberculin Skin Testing in Patients with HIV Infection: Limited Benefit of Reduced Cut-Off Values. Clinical Infectious Diseases, 43, 634-639. http://dx.doi.org/10.1086/506432

[16] Lao, L.Y. and De Guia, T. (1999) Tuberculin Skin Testing: Determinants and Reaction. Respirology, 4, $311-317$.

[17] Vekemans, J., Lienhardt, C., Sillah, J.S., Wheeler, J.G., Lahai, G.P., Doherty, M.T., Corrah, T., Andersen, P., McAdam, K.P.W.J. and Marchant, A. (2001) Tuberculosis Contacts but Not Patients Have Higher Gamma Interferon Responses to ESAT-6 than Do Community Controls in The Gambia. Infection and Immunity, 69, 6554-6557. http://dx.doi.org/10.1128/IAI.69.10.6554-6557.2001

[18] National Center for Biotechnology Information (1970) Tuberculin Anergy. British Medical Journal, 4, 573. http://dx.doi.org/10.1136/bmj.4.5735.573

[19] CDC (1991) Purified Protein Derivative (PPD)-Tuberculin Anergy and HIV Infection: Guidelines for Anergy Testing and Management of Anergic Persons at Risk of Tuberculosis. MMWR: Recommendations and Reports, 40, 27-33.

[20] Lienhardt, C., Fielding, K., Sillah, J., Tunkara, A., Donkor, S., Manneh, K., Warndorff, D., McAdam, K.P. and Bennett, S. (2003) Risk Factors for Tuberculosis Infection in Sub-Saharan Africa: A Contact Study in the Gambia. American Journal of Respiratory and Critical Care Medicine, 168, 448-455. http://dx.doi.org/10.1164/rccm.200212-1483OC

[21] Kang, Y.A., Lee, H.W., Yoon, H., Cho, B., Han, S.K., Shim, Y.S. and Yim, J.J. (2005) Discrepancy between the Tuberculin Skin Test and the Whole-Blood Interferon $\gamma$ Assay for the Diagnosis of Latent Tuberculosis Infection in an Intermediate Tuberculosis-Burden Country. JAMA, 293, 2756-2761. http://dx.doi.org/10.1001/jama.293.22.2756

[22] Legesse, M., Ameni, G., Mamo, G., Medhin, G., Bjune, G. and Abebe, F. (2010) Performance of QuantiFERON-TB Gold In-Tube (QFTGIT) for the Diagnosis of Mycobacterium tuberculosis (Mtb) Infection in Afar Pastoralists, Ethiopia. BMC Infectious Diseases, 10, 354. http://dx.doi.org/10.1186/1471-2334-10-354

[23] Chee, C.B.E., Gan, S.H., KhinMar, K.W., Barkham, T.M., Koh, C.K., Liang, S. and Wang, Y.T. (2008) Comparison of Sensitivity of Two Commercial Gamma Interferon Release Assay for Pulmonary Tuberculosis. Journal of Clinical Microbiology, 46, 1935-1940.http://dx.doi.org/10.1128/JCM.02403-07

[24] Kanunfre, K.A., Leite, O.H.M., Lopes, M.I., Litvoc, M. and Ferreira, A.W. (2008) Enhancement of Diagnostic Efficiency by a Gamma Interferon Release Assay for Pulmonary Tuberculosis. Clinical and Vaccine Immunology, 15, 1028-1030. http://dx.doi.org/10.1128/CVI.00026-08

[25] Kabeer, B.S.A., Raman, B., Thomas, A., Perumal, V. and Raja, A. (2010) Role of QuantiFERON-TB Gold, Interferon Gamma Inducible Protein-10 and Tuberculin Skin Test in Active Tuberculosis Diagnosis. PLoS ONE, 5, 9051-9057. http://dx.doi.org/10.1371/journal.pone.0009051

[26] Dagnew, A.F., Hussein, J., Abebe, M., Zewdie, M., Mihret, A., Bedru, A., et al. (2012) Diagnosis of Latent Tuberculosis Infection in Healthy Young Adults in a Country with High Tuberculosis Burden and BCG Vaccination at Birth. BMC Research Notes, 5, 415. http://dx.doi.org/10.1186/1756-0500-5-415

[27] Legesse, M., Ameni,G., Mamo, G., Medhin, G., Shawel, D., Bjune, G. and Abebe, F. (2012) Association of the Level 
of IFN- $\gamma$ Produced by T Cells in Response to Mycobacterium tuberculosis-Specific Antigens with the Size of Skin Test Indurations among Individuals with Latent Tuberculosis in a Highly Tuberculosis-Endemic Setting. International Immunology, 24, 71-78. http://dx.doi.org/10.1093/intimm/dxr102

[28] Park, Y.K., Lee, S.H., Kim, S.Y., Ryoo, S.W., Kim, C.K., Kim, H.J., Cho, E.H., Yoo, B.H., Lee, J.K. and Ko, W.J. (2010) Interferon- $\gamma$ Release Assay among Tuberculin Skin Test Positive Students in Korean High Schools. Tuberculosis and Respiratory Diseases, 68, 328-333. http://dx.doi.org/10.4046/trd.2010.68.6.328

[29] Cegielski, J.P. and McMurray, D.N. (2004) The Relationship between Malnutrition and Tuberculosis: Evidences from Studies in Humans and Experimental Animals. The International Journal of Tuberculosis and Lung Disease, 8, 286298.

[30] Semba, R.D., Darnton-Hill, I. and de Pee. S. (2010) Addressing Tuberculosis in the Context of Malnutrition and HIV Coinfection. Food and Nutrition Bulletin, 31, S345-S364.

[31] Zachariah, R., Spielmann, M.P., Harries, A.D. and Salaniponi, F.M. (2002) Moderate to Severe Malnutrition in Patients with Tuberculosis Is a Risk Factor Associated with Early Death. Transactions of the Royal Society of Tropical Medicine and Hygiene, 96, 291-294. http://dx.doi.org/10.1016/S0035-9203(02)90103-3

[32] Podewils, L.J., Holtz, T., Riekstina, V., Skripconoka, V., Zarovska, E., Kirvelaite, G., Kreigere, E. and Leimane, V. (2011) Impact of Malnutrition on Clinical Presentation, Clinical Course, and Mortality in MDR-TB Patients. Epidemiology \& Infection, 139, 113-120. http://dx.doi.org/10.1017/S0950268810000907 